\title{
Correction to: FoxO transcription factors regulate mouse preimplantation embryo development
}

\author{
Nilay Kuscu ${ }^{1} \cdot$ Nazli Ece Gungor-Ordueri $^{2} \cdot$ Berna Sozen $^{3} \cdot$ Dileyra Adiguzel $^{1} \cdot$ Ciler Celik-Ozenci $^{1}$ \\ Published online: 4 December 2019 \\ (C) Springer Science+Business Media, LLC, part of Springer Nature 2019
}

\section{Correction to: Journal of Assisted Reproduction and} Genetics (2019) 36:2121-2133. https://doi.org/10.1007/s10815-019-01555-1

The original article unfortunately contained a mistake. There is a misplaced " 1 " in the article title and the correct title is shown above.

The online version of the original article can be found at https://doi.org/ 10.1007/s10815-019-01555-1

Ciler Celik-Ozenci

cilerozenci@akdeniz.edu.tr

1 Department of Histology and Embryology, School of Medicine, Akdeniz University, Campus, 07070 Antalya, Turkey

2 Department of Histology and Embryology, School of Medicine, Biruni University, Istanbul, Turkey

3 Mammalian Embryo and Stem Cell Group, Department of Physiology, Development and Neuroscience, University of Cambridge, Cambridge CB2 3EG, UK 